\title{
Biomorphs Solanum dulcamara L. and their contribution in seasonal climate grasses origin
}

\author{
Irina Konovalova $^{1 *}$, and Natalya Savinykh ${ }^{1}$ \\ ${ }^{1}$ Centre competence "Usage of biological resourcer" of the Vyatka State University, 610000, Kirov, \\ Russia
}

\begin{abstract}
The paper demonstrates $S$. dulcamara ecobiomorphs: a long rhizome semi-woody liana (LSL), a long rhizome subshrub with ascending shoots (LSAS), a root sucker subshrub and a shortlived plants of vegetative origin; and ontobiomorphs: a taproot upright subshrub (TUS), a subshrub with a mixed root system (SMRS), LSL, and LSAS. Possible stages and modes are suggested of Solanum biomorph transformation: 1. TUS, as a result of prolongation on the shoot (adventitious roots) and shoot system level (two or more replacement shoots), deviations on individual plant level (shoot lodging), transforms into SMRS; 2. SMRS, through the plant's ontogenesis abbreviation (fragmentation), prolongation (epigeogenum rhizome), and deviation (stem twisting), transforms into LSL. Further LSL habit transformations can occur in xerophylous and hygrophylous biomorph evolution lines. On dry soil, as a result of prolongation (adventitious buds on roots), a root sucker subshrub appears. A hygrophyle line is possible in case of prolongations on the shoot level (metamere number increase within a shoot, dicyclic shoots), of the individual plant abbreviations (shortened life-time of sympodial axes, early fragmentation) and end with a short-lived plants of vegetative origin. Possibly, mien changes in S. dulcamara ontogenesis show possible stages in Solanum life forms transformation, from tree forms to LSL.
\end{abstract}

\section{Inrtoduction}

From ecological-morphological viewpoint, according to L. E. Gatsuk [1], the term "seasonal climate grasses" is applied to plants with annual above-ground orthotropic organs and buds either in substrate or on its surface. The origin of this biomorph group is one of the main issues of evolutional plant morphology. For 70 years, from the moment of Takhtajyan's publications [2] it has been considered by morphologists $[3 ; 4 ; 5 ; 6 ; 7 ; 1 ; 8 ; 9]$ and still remains topical $[10 ; 11 ; 12]$.

\footnotetext{
* Corresponding author: S-dulcamara@yandex.ru
} 
As a result, the analysis of researching plant mien and ontomorphogenesis has shown [7] that there are two ways of seasonal climate grasses origin: from pachycaulous (rosette) and leptocaulous (long-shoot) trees. In a set of taxons, such as Veronica [9], formation of seasonal climate grasses from the original long-shoot sclerocaulous forms without the liana stage was shown. In other taxons transformation includes the liana stage, thus such evolutional stages are called "liana" [1]. The most interesting among them are the biomorphs' transformations in the taxons, which are rich in life forms and are characterized by morphological flexibility of some representatives, which possibly could be viewed as intermediate ones in the habits' transformation line.

One of such genera is Solanum. It includes up to 1500 species, it is one of ten genera with the richest species composition and is the most widely represented of Solanaceae [13]. The taxonomy system of Solanum by foreign researches $[13 ; 14]$ is considered to be the most famous and of current use. It consists in genetically grounded clustering into 13 clades. The range of life forms of the genus was found out, they include small trees, lianas, shrubs, subshrubs, perennial and annual herbaceous plants. The main attention is paid to Dulcamaroid clade [15]. This clade includes $42 \%$ woody lianas and $7 \%$ semi-woody lianas. Like woody lianas, shrubs also account for $42 \%$, they are subdivided into plants with the life-form "a shub / a small tree" (22\%) and "an upright shrub" (20\%). The intermediate group (9\%) consists of the species which can develop either as a woody liana, or as an upright shrub, depending on the habitat factors.

As for the habit flexibility, the central place is taken by the semi-woody liana Solanum dulcamara L. (bittersweet) which is characteristic of moderate climate. This species shows a high level of morphological flexibility [16] and it serves as a model for researching molecule background of acclimatization and adaptation [17]. Unlike other representatives of Solanum originating from the tropics, bittersweet is a Eurasian species. As an adventurous plant and denizen, it is widely spread all over the Holarctic region. Due to its high ecological valence, $S$. dulcamara [16] occupies hydrologically contrasted media and it is included into vegetation communities different in degree of wetting and substrate. They include different types of coniferous forests, osier and alder formations, shrubs, shrubcovered steppe slopes, damp places in steppes, meadows, fields, gullies, banks of water bodies and sea shores, low swamps, and anthropogenically damaged places. Its habit's is being realization depends on environmental conditions, it takes place in the form of the following ecobiomorphs: semi-woody liana, subshrub with ascending shoots, root sucker subshrub, and a short-lived plant of vegetative origin [18].

The aim of the research is to find out the possible biomorphs (the basic biomorph, ontobiomorphs, ecobiomorphs) of $S$. dulcamara and to discuss their role in evolutional changes of life forms in formation of seasonal climate grasses.

\section{Materials and Research Methods}

The material of the research is represented by the units and separate shoot systems of S. dulcamara, which were studies within the period of 2011-2014 in different ecological conditions of Kirov region, Yaroslavl region, and Nizhniy Novgorod region. Some extra information on biomorphology of the species was got through analyzing the funds of the herbariums LE, MHA, SYKO, IBIW, TK, NS, NSK, MWV, MOSP, SYKT, and the herbarium collection of the VyatSU.

The research is based in describing definite structures according to the comparativelymorphological method, which was worked out by I. G. Serebryakov [19, 20]. Life form is characterized using multiple synthetic classification, ecological group is described according to V. G. Papchenkov [21, 22]. The modes of morphological evolution are assessed according to A. L. Takhtajyan [23], T. I. Serebryakova [6], A. P. Khokhryakov 
[24], and N. P. Savinykh [12]. The ways of origin of seasonal climate grasses, by the example of $S$. dulcamara, are discussed from the viewpoint of L. E. Gatsuk [1].

\section{Results and Discussion}

Ontogenesis of an individual plant of $S$. dulcamara is a successive line of several ontobiomorphs [25]. At an early generative stage it looks like a taproot upright subshrub (TUS), consisting of a set of acrosympodially growing axes from the series of monocarp shoots with two-three branching order (fig. 1 A): the innovation shoot (the original shoot in the axis) and sylleptic [16] shoots. S. dulcamara is characterized by branching which is typical of hygrophytes and hydrophytes, i. e. the way of branching with continuous development of branching shoots forming the plant axis during the vegetation period. It could be called a characteristic feature of the original forms which appeared as adapting to the tropical climate conditions and as a result of aperiodicity of the contemporary forms.

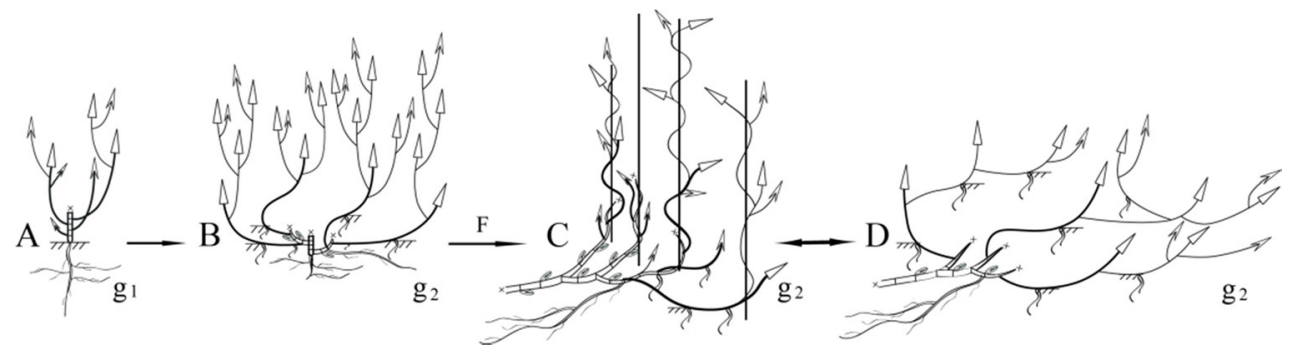

Fig. 1. Development of the basic life form of S. dulcamara: A - a taproot upright subshrub (TUS); B - a subshrub with a mixed root system (SMRS); C - long rhizome semi-woody liana (LSL); D - a long rhizome subshrub with ascending shoots (LSAS); F - fragmentation. The original shoots are marked with bold lines; leaves with axillar structures are not shown.

In course of time the number of monocarp shoots in the sympode grows. It causes changes in space position of shoots, from orthotropic to plagiotropic: the stem of the original shoot is laid and it roots. The basal parts with shoot-borne adventitious roots in their nodi and internodes are included into the shoot reproduction zone, later, as a residue, they form a sympodially growing rhizome epigeogenum. A subshrub with a mixed root system (SMRS) develops this way (fig. $1 \mathrm{~B}$ ).

As a result of normal full fragmentation the system of the plant's main root is changed into the system of shoot-borne adventitious roots. The basic life form of S. dulcamara [26] is formed, which is a summergreen vegetatively-mobile polycarpous polycentric sympodially branching long rhizome semi-woody liana (LSL) (fig. $1 \mathrm{C}$ ). Irrespective of the conditions in which the plant grows, the shoots of bittersweet try to find anything to cling to and then entwining about the supporter they try to catch the most of the light possible for the assimilating surface. Without any support the shoots get lodged with only their tops staying upright, and a special life form appears - a long rhizome subshrub with ascending shoots - LSAS (fig. $1 \mathrm{D})$.

The S. dulcamara biomorphs described successively changing each other are represented in the life form range of Dulcamaroid clade. Thus according to the biogenetic law, taking into account the geographical and systematical characteristics of the genus, it is possible to name the following stages and modes of possible transformations of Solanum biomorphs: 1. TUS, as a result of prolongations of the shoot (shoot-borne adventitious roots) and of the shoot system (development of substitution shoots of from the second up to fifth order of branching), as well as deviations within the individual plant (shoot lodging), transforms into SMRS; 2. SMRS in conditions of ontogenesis abbreviation of the individual 
plant (fragmentation), prolongation (rhizome epigeogenum), and deviation (stem twisting) transforms into LSL. Prolongation in development of shoot systems and the plant's formation in the form of liana is caused by abbreviating the budding state in a monocarp shoot's development [12].

Further transformations of bittersweet habit were possible in case of xerophile and hygrophile evolution lines of biomorphs. On dry sandy soils, as a result of prolongation (with adventitious buds developing on shoot-borne adventitious roots), grows a root sucker subshrub. Other habit changes were not stated in the conditions. Probably, the xerofile evolution line of bittersweet could be considered as a nonbasic and still not finished one.

The most considerable changes take place in cases when plants of S. dulcamara acclimatize in aquatic habitat. Taking into account the approaches [27] to pointing out ecological groups of water body plants, it was found out that the most typical place of bittersweet habitat in conditions of variable flooding are low and mid levels of the flood water zone. In the first case, $S$. dulcamara as a hygrohelophyte is met at littoral shafts up to 20-40 sm deep, it occupies wet scarcely flooded grounds, quite often it is included into the sides of floating mats (fig. 2 A). When bittersweet grows on mid levels of the floodline it shows itself as a wet places plant (hygrophyte), and it often grows in water at low marshy banks (fig. 2 B). Like a helophyte it occupies shallow waters up to $1 \mathrm{~m}$ deep near banks. Here a special water ecobiomorph of $S$. dulcamara is developed (fig. 2 C): a short-lived plant of vegetative origin.

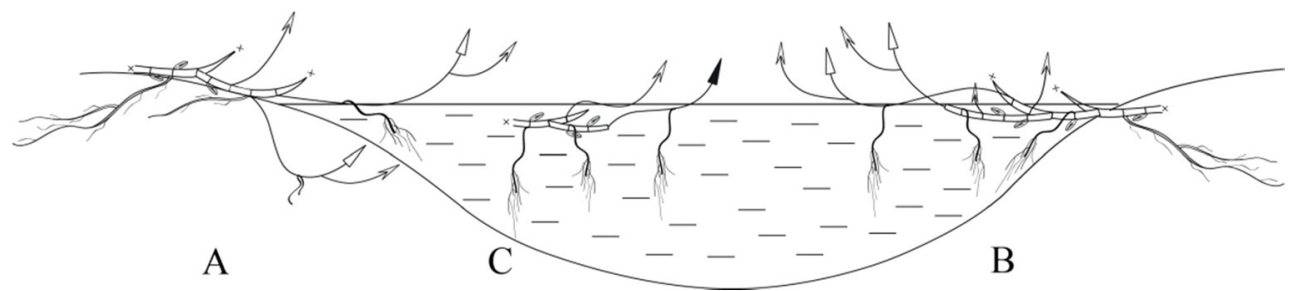

Fig. 2. Hygrophile line of $S$. dulcamara life form transformation: A - hygrohelophyte; B hygrophyte; $\mathrm{C}$ - helophyte.

Thus $S$. dulcamara can be considered a coastal species in a broad sense, included it into the complex of semi-aquatic and in-water coastal plants. Evidently its place is where water macrophytes get on the land, and land plants get into water, according to V. G. Papchenkov [22].

In course of inhabiting a water body plant root system and shoot system are transforming. In water conditions shoot-borne adventitious roots develop, they are cordlike, evenly incrassate, and caulogenuos, like those of the land form. But they are green in colour, during the second year they branch and on top many long etiolated roots appear. The roots are characterized by two-three order branching. They absorb mineral substances and "anchor" the plant near the shore, participate in photosynthesis through accumulating chlorophyll in the cells of parenchyma. Such adventitious roots are developing along the stem from the point of its being put into water, and how far the plant is growing from the shore does not influence their structure. This new formation is considered as prolongation on the level of a definite monocarpic shoot.

There also are some changes in the shoot system structure. Within hygrohelophyte communities the shoot system of the plant develops as a sympode-monochasium. The number of monocarpic shoots on the axis shortens up to two-three (fig. 2 A). This reduction is probably compensated for increase in the number of metameres in the structure of these shoots (often up to 35). In this case two evolutional modes take place at the same time, such as terminal abbreviation on the level of the shoot system and prolongation on the level of 
the system's elements (monocarpic shoots). Iterative branching remaining, the structure of the sympodial axis of the biomorph becomes simpler.

In such conditions $S$. dulcamara can propagate both in a vegetative way and by means of seed reproduction; there seed plants of a different age on the banks of the water bodies. With advancing into water this ability is lost (seeds cannot sprout in water), and only vegetative reproduction takes place.

Hygrophytes development causes one more anaboly (terminal prolongation) on the level of the shoot: formation of dicyclical monocarpic shoots (fig. 2 B). The main reasons of this are stability of water medium and aperiodicity of the plant. Prolongation of the phase of a vegetative assimilating shoot in its morphogenesis is of great importance from the biological viewpoint: the plant is effectively using the living space and acclimatizing to it.

Bittersweet is not often met as a helophyte. Appearing of a water life form is determined by shoot systems growth direction: here - from the shore deep down a water body. Under the circumstances, dying away (stem internodes decay) dominates the process of growing, fragmentation is early. As a result, the plant does not live long, its branching is scarce - it is a short-lived plant of vegetative origin (fig. 2 C). Here the main issue consists in reduction of seed reproduction propagation: the inflorescence is formed but it does not develop. Selfmaintaining of the plants is only vegetative, ramets' ontogenesis is incomplete. The changes under research are viewed as abbreviations, such as terminal (inflorescence reduction) and basal (early fragmentation, shortening of shoot systems' lifetime and reduction of their number); they lead to ontogenesis abbreviation of an individual plant. According to N. P. Savinykh [12], it is the basic mode of biomorphs' evolutional transformations at plants' getting into water environment.

In water ontogenesis of a short-lived plant of vegetative origin is terminated on the border of virginile and early generative ontogenetic stage. It is possible, that the water ecobiomorph of $S$. dulcamara could be considered as an example of neoteny.

\section{Conclusion}

The result of the research let us suppose that the changes in the habit of S. dulcamara individual plants demonstrate possible stages of Solanum life from transformations, from woody upright forms to semi-woody long rhizome lianas. On the other hand, they demonstrate possible further transformations of semi-woody lianas in xerofilous and hygrophilous evolution lines. Evidently, the evolutional process of seasonal climate grasses in conditions of the current geologic time is not yet finished.

This research was conducted with financial support from the Russian Foundation for Basic Research (project no. 16-04-01073).

\section{References}

1. L. E. Gatsuk, Proceedings of the Moscow Society of Naturalists, 42, 55 (1976)

2. A. L. Takhtajyan, Morphological evolution of angiosperms (1948)

3. I. G. Serebryakov, Bull. of the Moscow Society of Naturalists, Dep. biol., 60, 71 (1955)

4. V. N. Golubev, Bull. of the Moscow Society of Naturalists, Dep. biol., 78, 90 (1973)

5. T. I. Serebryakova, Morphogenesis of shoots and the evolution of life forms of cereals (1971)

6. T. I. Serebryakova, Journ. of General Biology, 44, 579 (1983)

7. L. E. Gatsuk, Bull. of the Moscow Society of Naturalists, Dep. biol., 79, 100 (1974) 
8. A. P. Khokhryakov, Bull. of the Moscow Society of Naturalists, Dep. biol., 78, 59 (1973)

9. N. P. Savinykh, Bull. of the Moscow Society of Naturalists, Dep. biol., 91, 64 (1986)

10. I. A. Savinov, Turczaninowia, 14, 53 (2011)

11. A. A. Notov, Advances in modern science, 3, 145 (2015)

12. N. P. Savinykh, Proceedings of the Russian Academy of Sciences. Biol. Ser., 1, 72 (2019)

13. L. Bohs, Missouri Botanical Garden Press, 104, 27 (2005)

14. T. L. Weese, L. Bohs, Systematic Botany, 32, 445 (2007)

15. S. Knapp, PhytoKeys, 22, 1 (2013)

16. I. A. Zhuravleva, N. P. Savinykh, Bull. of Tver State University, 25, 101 (2012)

17. N. D’Agostino, T. Golas, H. van de Geest, A. Bombarely, T. Dawood, J. Zethof, N.Driedonks, E. Wijnker, J. Bargsten, J.-P. Nap, C. Mariani, I. Rieu, BMC Genomics, 14 (2013)

18. N. P. Savinykh, I. A. Konovalova, Biology Bulletin, 46, 570 (2019)

19. I. G. Serebryakov, Morphology of the vegetative organs of higher plants, 391 (1952)

20. I. G. Serebryakov, Scientific notes of the Moscow City Pedagogical Institute named after V. P. Potemkin, 372, 3 (1954)

21. V. G. Papchenkov, Ecology, 6, 8 (1985)

22. V. G. Papchenkov, On the classification of plants of water bodies and watercourses, in the materials of the School of Hydrobotany, 23 (2003)

23. A. L. Takhtajyan, Issues of evolutionary plant morphology, 216 (1954)

24. A.P. Khokhryakov, Zh. general biology, 35, 331 (1974)

25. I.A. Zhuravleva, N.P. Savinykh, Bull. of Tyumen. St. University, 6, 7 (2013)

26. N. P. Savinykh, I. A. Konovalova, Bull. of the Russian Academy of Sciences. Ser. biol., 6, 607 (2019)

27. A. G. Lapirov, Ecological groups of water body plants: in the materials of the Hydrobotany School, 5 (2003) 